\title{
Avaliação cefalométrica em norma lateral entre indivíduos Classe I e II esqueléticas com a maturação óssea das vértebras cervicais*
}

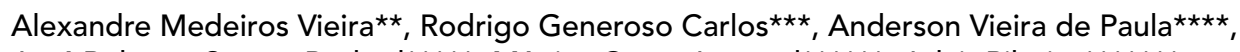

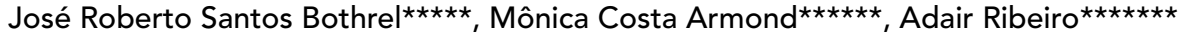

\section{Resumo}

Objetivo: o objetivo deste trabalho foi averiguar a existência de diferenças no efetivo da face média (Co-A) entre indivíduos dos gêneros masculino e feminino, leucodermas, apresentando padrões esqueléticos Classe I e Classe II, na faixa etária dos sete aos treze anos, apresentando as mesmas fases de maturação óssea das vértebras cervicais. Metodologia: a amostra foi formada por 160 radiografias cefalométricas laterais de indivíduos sem prévio tratamento ortodôntico ou ortopédico facial. Resultados: os resultados mostraram não existir diferenças estatisticamente significantes entre os indivíduos com padrão esquelético Classe I e padrão esquelético Classe II, nem entre os gêneros masculino e feminino. Apenas a variação da medida Co-A na fase 1 (iniciação) de maturação das vértebras cervicais foi estatisticamente menor do que as demais fases ( 2 = aceleração, 3 = transição e 4 = desaceleração) nos dois grupos estudados. Conclusão: dessa forma, concluímos que tanto indivíduos apresentando padrões esqueléticos Classe I como Classe II, dos gêneros masculino e feminino, apresentaram o comprimento efetivo da face média semelhante, nas fases de maturação óssea das vértebras cervicais estudadas.

\section{Palavras-chave: Comprimento da maxila. Padrão esquelético Classe II. Idade esquelética. Vértebras} cervicais.

\section{INTRODUÇÃO}

$\mathrm{O}$ crescimento equilibrado das estruturas craniofaciais, dentre elas a maxila e a mandibula, é um aspecto importante no diagnóstico e prognóstico ortodôntico e ortopédico-facial ${ }^{15,17,25}$. Assim, podemos citar como equilíbrio o padrão esquelético Classe I, que apresenta-se como um padrão harmonioso de crescimento entre as bases ósseas, sendo muito utilizado pelos profissionais como referência para o tratamento das demais más oclusões de origem esquelética. Já o padrão esquelético Classe II se manifesta como um desequilíbrio no crescimento entre as bases ósseas, causado por protrusão da maxila ( $20 \%$ dos casos), retrusão da mandíbula ou uma combinação de ambas ${ }^{27,31,32}$. A partir desta constatação, torna-se importante

* Resumo de dissertação de mestrado em Clínica Odontológica apresentada à Universidade Vale do Rio Verde, de Três Corações (UninCor - MG).

* Mestre em Clínica Odontológica (UninCor/MG). Doutorando em Ortodontia - CPOSLMandic/SP. Professor dos Cursos de Pós-graduação a nível de Especialização em Ortodontia pela FUNORTE/GAPO - Contagem/MG e FUNORTE/ IMPG - Alfenas /MG.

Professor Titular de Ortodontia. Doutor em Odontologia UninCor-MG.

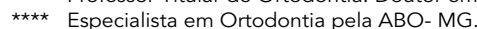

$\star \star \star \star \star \star ~ O r t o d o n t i s t a$, Mestre em Clínica Odontológica UninCor-MG

$\star \star \star \star \star \star \star$ Radiologista, Mestra e Doutora em Radiologia UninCor-MG.

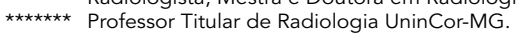


estabelecer as características do comprimento da maxila entre indivíduos portadores de padrões esqueléticos Classes I e II em fase de crescimento, a fim de que se possa diagnosticar e tratá-los com a melhor conduta terapêutica.

Para tanto, é relevante a determinação da idade esquelética, que é a real referência da idade biológica de uma pessoa. Usualmente, para estimar a idade esquelética em que o indivíduo se encontra utilizase a radiografia carpa ${ }^{19,29}$. Contudo, outros métodos de avaliação da idade esquelética têm sido estudados, como a inspeção das fases de maturação óssea das vértebras cervicais vistas em radiografias cefalométricas laterais, as quais fazem parte da documentação ortodôntica de rotina, sendo que esse método apresenta uma tendência atual com grande confiabilidade descrita na literatura ${ }^{1,2,7,8,9,10,11,16,20,26,30}$. Além disso, com a utilização desse método, pode-se diminuir a quantidade de radiação ionizante a que o paciente é exposto, pois elimina o uso de radiografias adicionais, como a carpal28.

Alguns trabalhos apresentados na literatura mostram existir correlação estatisticamente significante entre o aumento do comprimento mandibular e a diferenciação morfológica das fases de maturação óssea das vértebras cervicais ${ }^{3,6,18}$.

Sendo assim, como o padrão esquelético Classe II tem o fator etiológico protrusão maxilar correspondente a $20 \%$ dos casos, faz-se necessário determinar possiveis diferenças no comprimento maxilar entre indivíduos apresentando padrões esqueléticos Classe I e Classe II, estando nas mesmas fases de maturação óssea vertebral, ou seja, estando na mesma idade esquelética ${ }^{23}$. Prates et al. ${ }^{23}$ realizaram um estudo em 40 indivíduos com oclusão normal, dos gêneros masculino e feminino, em idades variando de onze a quinze anos completos. A fim de evidenciar as características de sete medidas cefalométricas e as características das áreas de oito ossos carpais, compararam as evidências entre elas, relativas a cada gênero, quanto ao processo de crescimento e desenvolvimento esquelético. Concluíram que todas as medidas cefalométricas estudadas mostraram cres- cimento maior para o gênero masculino, no entanto, para o gênero feminino foi possivel evidenciar crescimento apenas para duas medidas cefalométricas. Com relação às áreas dos oito ossos carpais, todas evidenciaram crescimento substancial para o gênero masculino, enquanto para o gênero feminino apenas algumas áreas evidenciaram um crescimento discreto. Os processos de crescimento e de desenvolvimento esquelético foram melhor evidenciados na área carpal, para ambos os gêneros, e as taxas de crescimento dos ossos carpais foram mais altas para o gênero masculino. Cuoghi ${ }^{5}$ avaliou o complexo maxilomandibular de pacientes tratados ortodonticamente com extração de quatro pré-molares, utilizando as medidas de análise cefalométrica de $\mathrm{McNamara}^{17}$, Co-A, Co-Gn, diferença maxila/mandíbula e AFAI. A amostra constou de 66 telerradiografias laterais de 22 jovens do gênero feminino, obtidas no início, no final e dez anos após o término do tratamento ortodôntico, cujas idades médias correspondiam a doze anos e nove meses, 15 anos e três meses e 27 anos e dez meses, respectivamente. No início do tratamento, nove apresentavam má oclusão Classe I esquelética e treze Classe II esquelética. Os resultados demonstraram que o comprimento efetivo da maxila (Co-A) mostrou-se semelhante nas más oclusões de Classe I e Classe II esqueléticas no início do tratamento, manifestando um semelhante aumento durante o tratamento e dez anos após a sua conclusão, em ambos os grupos estudados. Pinzan et al. ${ }^{21}$ correlacionaram os dados de dois estudos sobre o crescimento maxilomandibular $^{15,17}$, utilizando as seguintes medidas: Co-A, Co-Gn, diferença maxila/mandíbula e AFAI. Analisando os resultados, relataram que o crescimento no gênero feminino ocorre antes do masculino, cessando o seu pico por volta dos treze anos nas meninas. Segundo eles, a medida Co-A (comprimento efetivo da face média ou maxila) revela, inicialmente, um valor menor aos cinco anos para o gênero feminino, que se comporta de forma semelhante ao do gênero masculino com o envolver da idade até os 11 anos. Dos 11 aos 13 anos evidencia-se um crescimento 
bastante discreto para ambos. A partir dos 13 anos até os 17 anos observa-se um estirão de crescimento mais acentuado para o gênero masculino. Como o estudo limitou as idades de 17 anos e 10 meses para o gênero masculino e 17 anos para o gênero feminino, seria de suma importância continuar a seguir a amostra em questão para adquirir e interpretar novos dados, pois pelos gráficos do estudo percebe-se que os valores para o gênero masculino são ascendentes, denotando continuidade de crescimento facial. Prata et al. ${ }^{22}$ verificaram qual a relação existente entre o crescimento na fase de aceleração do surto de crescimento puberal e o crescimento maxilar e mandibular, pelo método radiográfico em indivíduos dos gêneros masculino e feminino. Esta pesquisa teve como objetivo comparar o crescimento maxilar e mandibular entre a fase do início e a fase do pico do surto puberal, além de verificar se existem diferenças entre os parâmetros do crescimento maxilar e mandibular entre esses indivíduos. Foram utilizadas 93 radiografias carpais e 186 radiografias cefalométricas laterais, na faixa etária entre sete e treze anos. As radiografias carpais e telerradiografias foram divididas com relação ao gênero e ao período em que se encontravam na curva de crescimento puberal, em grupos I e II, correspondendo ao início e ao pico de crescimento puberal, respectivamente. Os autores concluíram que não houve diferença estatiscamente significante para os incrementos de cada medida cefalométrica linear estudada (Co-A, Co-Go, Go-Gn, Co-Gn) entre os grupos I (início do $\mathrm{SCP}$ ) e II (pico do SCP), tanto para os meninos quanto para as meninas, sugerindo um crescimento maxilo-mandibular linear durante a fase de aceleração do surto puberal. Riedel ${ }^{24}$ descreveu algumas medidas cefalométricas, utilizando como referência a base do crânio (linha Sela-Nasio) e o plano de Frankfurt (linha Porio-Orbita). O autor pesquisou 52 pacientes adultos com oclusão normal e idade variando dos 18 aos 36 anos e, ainda, 24 pacientes jovens, também com oclusão normal e idade variando dos 7 aos 11 anos. A posição da maxila em relação à base do crânio no sentido ântero-posterior, denominada de ângulo SNA, foi comparada entre as amostras e apresentou os seguintes valores médios: 82,01 e desvio-padrão de 3,89 para a primeira amostra e 80,79 com desvio-padrão de 3,85 na segunda amostra. Também a posição da mandíbula em relação à base do crânio no sentido ântero-posterior, denominada ângulo SNB, foi comparada entre as amostras e apresentou os seguintes valores médios: 79,97 e desvio-padrão de 3,60 para a primeira amostra e 78,02 com desvio-padrão de 3,06 na segunda amostra. Já a diferença no posicionamento ânteroposterior entre a maxila e a mandíbula, ou seja, a diferença entre os ângulos SNA e SNB, denominada ângulo $\mathrm{ANB}$, mostrou os seguintes valores médios para as amostras: 2,04 com desvio padrão de 1,81 na primeira amostra e 2,77 com desvio-padrão de 2,33 na segunda amostra. Os pontos A e B em pacientes com oclusão normal apresentaram uma relação constante com o plano oclusal, sendo que a linha que une esses pontos apresentou aproximadamente $90^{\circ}$ com esse plano. Jacobson ${ }^{12,13,14}$ apresentou um trabalho demonstrando a avaliação Wits (University of the Witwatersrand ) na busca por uma relação de medidas que avaliasse, de maneira fiel, as discrepâncias ântero-posteriores da face, sem depender das medidas angulares da base do crânio. $\mathrm{O}$ autor estudou uma amostra de 21 pacientes do gênero masculino e 25 do gênero feminino, baseada em oclusão normal, objetivando correlacionar as bases ósseas de uma maneira simplificada e ao mesmo tempo fiel. Para tal, adotou os pontos A e B, traçou uma linha perpendicular ao plano oclusal funcional e chamou a interseção destas linhas de ponto $\mathrm{AO}$ e ponto $\mathrm{BO}$. Segundo a média encontrada nos resultados de sua pesquisa, Jacobson avaliou que, nas mulheres, os pontos $\mathrm{AO}$ e $\mathrm{BO}$ coincidiam, ou seja Wits era igual a zero, e nos homens o ponto $\mathrm{BO}$ situava-se $1 \mathrm{~mm}$ à frente de AO (Classe I esquelética). Já na relação de Classe II esquelética o ponto $\mathrm{BO}$ estaria bem atrás do ponto AO, estabelecendo uma leitura positiva; e numa relação de Classe III esquelética o ponto $\mathrm{BO}$ estaria à frente do ponto $\mathrm{AO}$, estabelecendo uma leitura negativa. As vantagens de se utilizar a avalia- 
ção Wits seria a não-dependência de medidas angulares, diminuindo a margem de erros, pois essa medida relaciona somente medidas lineares individualizadas a cada pessoa pelo plano oclusal funcional. Canuto ${ }^{4}$ realizou um estudo da avaliação cefalométrica das relações ântero-posteriores das bases apicais superior e inferior, em casos de oclusão normal, comparando dois tipos de análises Wits de Jacobson $^{12,13}$ e ângulo ANB de Riedel ${ }^{24}$. A amostra constou de quarenta telerradiografias em norma lateral, obtidas de pacientes brasileiros, leucodermas, dos gêneros masculino e feminino, não tratados ortodonticamente e portadores de oclusão normal, entre as idades de doze e dezessete anos. Após avaliação estatística, e diante dos resultados obtidos, os autores concluíram que não houve diferença estatística entre as médias com relação ao gênero; estatisticamente, houve correlação entre as análises empregadas (ANB e Wits), quando comparadas entre si. Quanto maior o ângulo ANB, maior a distância AOBO. As análises empregadas (ANB e Wits), quando estudadas em relação às demais grandezas cefalométricas, mostraram correlação estatística significante apenas do ângulo ANB com o ângulo SNA e da distância AO-BO com o ângulo NS-GoM.

\section{PROPOSIÇÃO}

Comparar o comprimento efetivo da face média, por meio da medida Co-A, entre indivíduos apresentando padrão esquelético Classe I e padrão esquelético Classe II, dos gêneros masculino e feminino, estando nas mesmas fases de maturação óssea das vértebras cervicais.

\section{MATERIAL E MÉTODOS}

De um total de 520 radiografias cefalométricas laterais do arquivo da Clínica de Ortodontia/Ortopedia Funcional dos Maxilares da Universidade Vale do Rio Verde (UNINCOR), na cidade de Três Corações-MG, foram selecionadas e analisadas para esta pesquisa 160 radiografias cefalométricas laterais. Para critério de inclusão na amostra, as radiografias apresentavam adequada visualização das estruturas craniofaciais, assim como das vértebras cervicais. A amostra foi formada por indivíduos dos gêneros masculino e feminino, leucodermas, na faixa etária dos sete aos treze anos, apresentando padrão esquelético Classe I e padrão esquelético Classe II, em fase inicial de tratamento, ou seja, sem terem sido submetidos a qualquer tipo de tratamento ortodôntico/ortopédico prévio. As radiografias cefalométricas laterais foram pré-selecionados em quatro grupos para o gênero masculino, portadores de padrão Classe I e padrão Classe II, e quatro grupos para o gênero feminino, portadores de padrão Classe I e padrão Classe II, correspondentes às quatro primeiras fases $(1=$ iniciação, 2 = aceleração, 3 = transição, 4 = desaceleração) de maturação óssea das vértebras cervicais, segundo Hassel e Farman ${ }^{10}$, sendo 10 radiografias por fase. A inspeção das fases foi realizada por um único examinador devidamente treinado, observando as características morfológicas das vértebras $\mathrm{C} 2, \mathrm{C} 3 \mathrm{e}$ C4 (Fig. 1 - 6).

Os valores cefalométricos foram obtidos em traçados computadorizados, sendo utilizados para tal: computador, mesa digitalizadora, negatoscópio e software SIDCCC for Windows. Na confecção destes, foram utilizados os seguintes pontos, linhas e planos:

- ponto N (násio): localizado na parte mais anterior da sutura frontonasal que a glabela aos ossos nasais;

- ponto S (sela): ponto virtual situado no centro da sela túrcica;

- ponto A: localizado na porção anterior da maxila, na maior profundidade da curva formada pelo perfil alveolar, no ponto em que ela se une ao perfil da espinha nasal anterior;

- ponto B: localizado na porção anterior da mandíbula, na maior profundidade da curva formada pelo perfil alveolar, no ponto em que ela se une ao perfil do mento;

- ponto Co (condílio): ponto mais póstero-superior do contorno dos côndilos mandibulares;

- ponto AO: ponto de interseção da perpen- 
dicular traçada do ponto A ao plano oclusal funcional;

- ponto BO: ponto de interseção da perpendicular traçada do ponto B ao plano oclusal funcional;

- linha N-A: linha que une o ponto $\mathrm{N}$ ao A;

- linha N-B: linha que une o ponto N ao B;

- linha Co-A: linha que une o ponto Co ao ponto A;

- linha AO: linha que une o ponto A ao plano oclusal;

- linha BO: linha que une o ponto B ao plano oclusal;

- plano oclusal funcional traçado passando pelo ponto médio da união da superposição das cúspides mesiovestibulares dos primeiros molares permanentes e as cúspides vestibulares dos primeiros pré-molares;

- avaliação Wits (University of the Witwatersrand): medida linear entre os pontos $\mathrm{AO}$ e $\mathrm{BO}$, sobre o plano oclusal funcional;

Para a determinação da relação esquelética entre maxila e mandíbula, foram considerados indivíduos portadores de padrão esquelético Classe I, aqueles que apresentassem o ângulo ANB (overjet ósseo) de dois graus, com variação de dois graus para mais ou para menos (de 0 a 4 graus) e portadores de padrão esquelético Classe II, aqueles

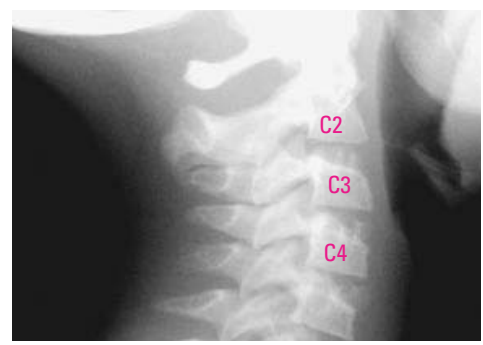

FIGURA 1 - Fase 1 Iniciação: nesse estágio, 0 cres cimento e desenvolvimento puberal do pacientes, estão no seu início, existindo uma expectativa de crescimento de $80 \%$ a $100 \%$. As bordas inferiores de C2, C3 e C4 estão achatadas ou planas. As bordas superiores dessas vértebras encontram-se afuniladas de posterior para anterior.

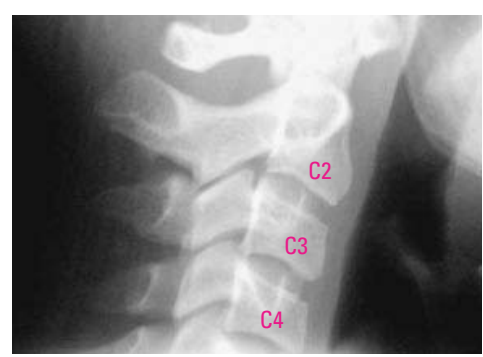

FIGURA 4 - Fase 4 Desaceleração: ocorre grande desaceleração do crescimento puberal nesse estágio e a expectativa de crescimento é de $10 \%$ a $25 \%$. 0s bordos inferiores de C2, C3 e C4 apresentam-se com concavidades distintas. Os corpos vertebrais de C3 e C4 aproximam-se do formato quadrado.

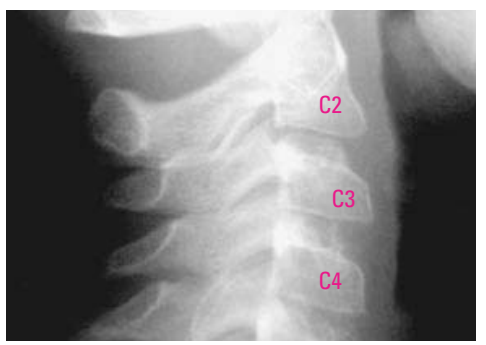

FIGURA 2 - Fase 2 Aceleração: o crescimento e desenvolvimento puberal do paciente já iniciaram, existindo uma expectativa de crescimento de $65 \%$ a $85 \%$. As bordas inferiores de C2 e C3 começam a apresentar concavidades, porém a borda inferior de C4 ainda apresenta-se plana ou achatada. Os corpos vertebrais de $\mathrm{C} 3$ e C4 apresentam-se com formato aproximadamente retangular.

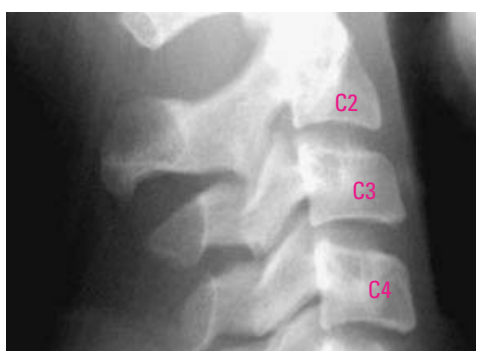

FIGURA 5 - Fase 5 Maturação: o final da maturação vertebral ocorre nessa fase e a expectativa de crescimento é de apenas $5 \%$ a $10 \%$. 0 s bordos inferiores de C2, C3 e C4 encontram-se com concavidades mais acentuadas. 0 formato dos corpos vertebrais de C3 e C4 apresentam-se com o formato quadrado.

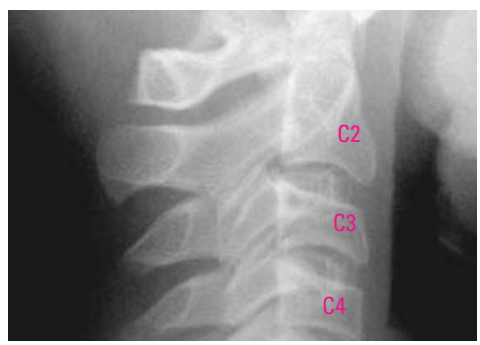

FIGURA 3 - Fase 3 Transição: o crescimento puberal está diminuindo sua aceleração, mas ainda apresenta de $25 \%$ a $65 \%$ de expectativa de crescimento. C2 e C3 apresentam-se com concavidades distintas em suas bordas inferiores e C4 apresenta-se com início da concavidade no bordo inferior. Os corpos vertebrais de C3 e C4 apresentam-se com formato retangular.

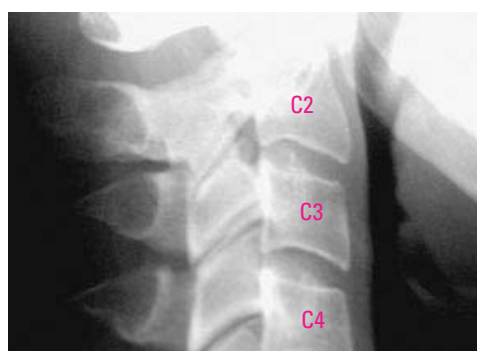

FIGURA 6 - Fase 6 Finalização: 0 crescimento é considerado completo nessa fase e a expectativa de crescimento puberal é nula ou mínima. 0s bordos inferiores de C2, C3 e C4 apresentamse com concavidades bem definidas. Os corpos vertebrais de $\mathrm{C} 3 \mathrm{e} \mathrm{C} 4$ apresentam-se maiores em altura (sentido vertical) do que em largura (sentido horizontal). 
que apresentassem o ângulo ANB (overjet ósseo) maior ou igual a cinco graus ${ }^{24}$, conforme é demonstrado nas figuras 7 e 8 .

Para confirmação da relação esquelética também foi feita a avaliação Wits, sendo considerados padrão esquelético Classe I aqueles indivíduos que apresentassem valores entre menos um e zero (ponto $\mathrm{BO}$ à frente do ponto $\mathrm{AO}$ ou coincidente), e padrão esquelético Classe II aqueles que apresentassem medidas positivas (ponto $\mathrm{AO}$ à frente do ponto $\mathrm{BO}$ ), conforme figura 9 .

O comprimento efetivo da face média, descrito por Mcnamara ${ }^{17}$, foi determinado por meio da

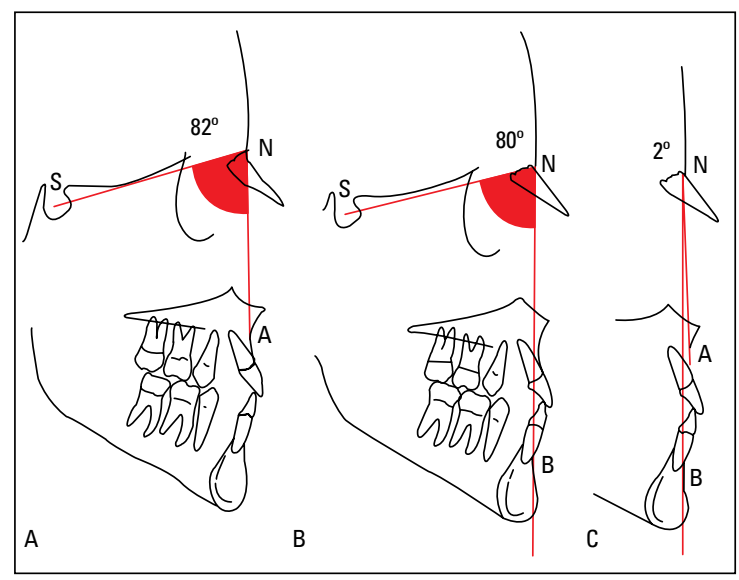

FIGURA 7 - A, B, C) Medição do ângulo ANB, formado a partir da medição dos ângulos SNA e SNB. medida linear entre os pontos Co e A (Fig. 10).

Os valores encontrados para a medida $\mathrm{Co}-\mathrm{A}$ nos indivíduos padrões Classes I e II esqueléticos, em suas respectivas fases vertebrais, foram comparados estatisticamente, com o objetivo de avaliar a influência dos fatores: gênero, padrões Classes I e II esqueléticos e fases 1, 2, 3 e 4 na variação da média da medida Co-A. Portanto, foi avaliada a influência do gênero na Classe e na fase, bem como a interação entre os 3 fatores (gênero X Classe, gênero X fase, Classe X fase, gênero X Classe X fase). Quando a análise apresentou influência significativa de algum desses fatores, utilizou-se o teste de comparações

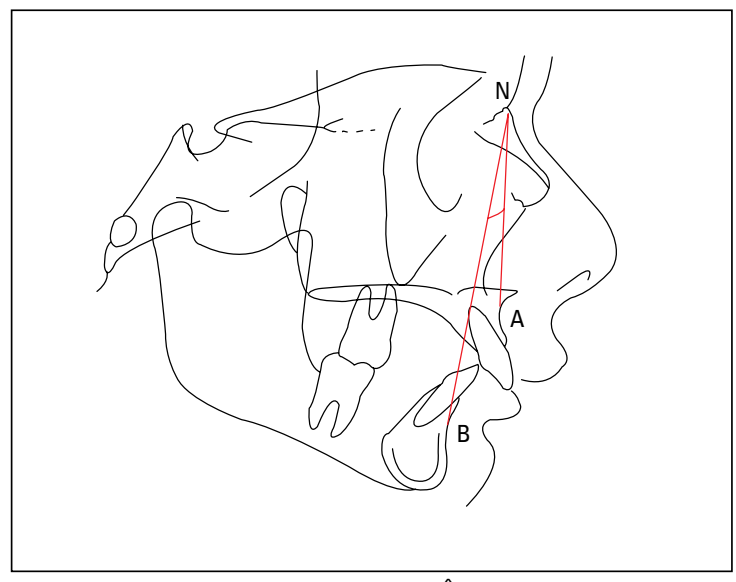

FIGURA 8 - Relação esquelética de Classe II. Ângulo ANB > 50.

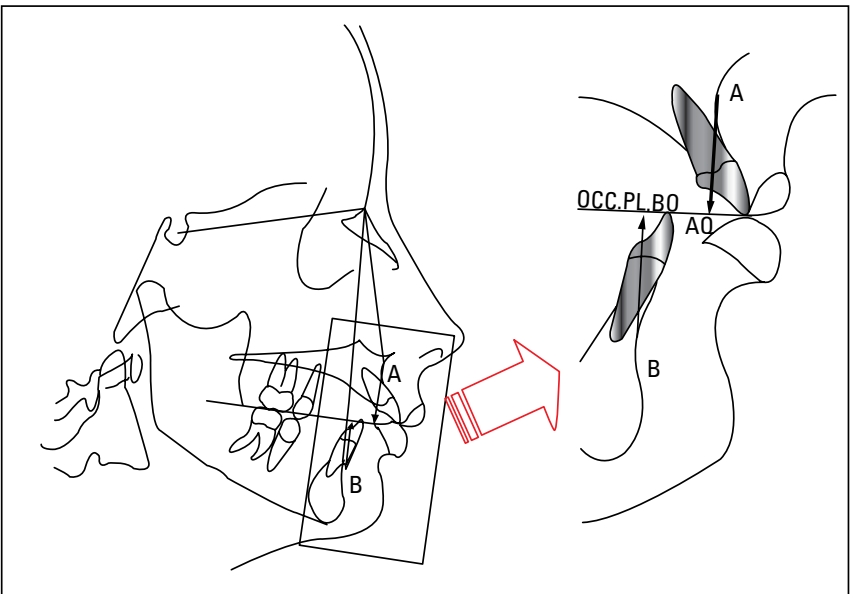

FIGURA 9 - Determinação da medida Wits, a partir da projeção dos pontos A e B no plano oclusal funcional. 
múltiplas de médias de DUNCAN para detectar realmente onde ocorreram as diferenças. Os resultados foram considerados significativos quando o nível de significância foi de $5 \%(\mathrm{p}<0,05)$, tendo, por conseguinte, $95 \%$ de confiança de que os resultados estivessem corretos.

\section{RESULTADOS}

No gráfico 1 pode-se observar a totalidade da amostra estudada, formada por radiografias cefalométricas laterais de indivíduos dos gêneros masculino e feminino, portadores de padrão Classe I e padrão Classe II, na faixa etária de sete a treze anos, perfazendo um total de 160 radiografias.

A tabela 1 mostra que apenas o fator fase teve influência estatisticamente significante $(p<0,05)$ sobre a avaliação da medida Co-A, isto é, independentemente do gênero dos indivíduos e do padrão esquelético. Portanto, não existiram diferenças significativas entre os indivíduos dos gêneros masculino e feminino, nem diferença significativa entre os padrões Classes I e II. Além disso, as interações entre os fatores não se mostraram significativas ( $\mathrm{p}>0,05)$; portanto, não há influência de um fator no nível de outro para a medida de Co-A, ou seja, o comportamento de um fator é semelhante ao nível do outro fator.

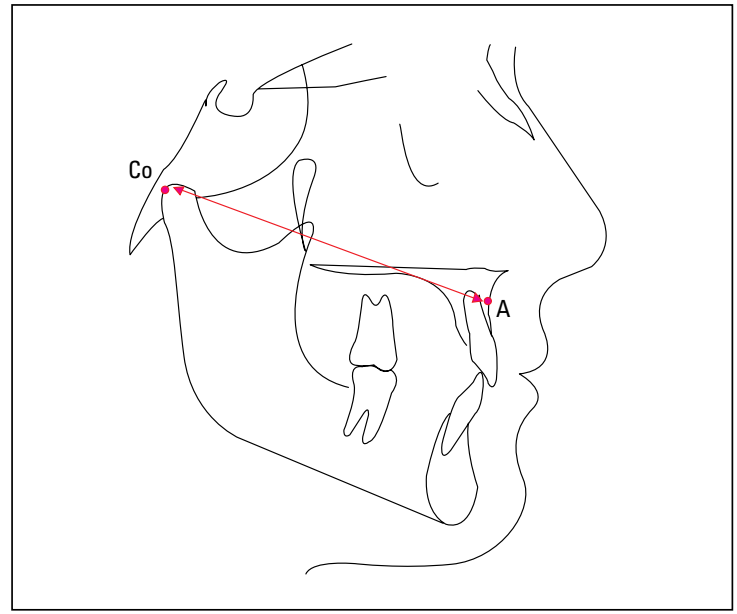

FIGURA 10 - Medida do ponto Co ao ponto A, utilizada para determinação do comprimento efetivo da face média.

\section{DISCUSSÃO}

Muito se tem estudado sobre os métodos de avaliação da idade biológica de um indivíduo com o objetivo de determinar as várias etapas de crescimento, principalmente na época da puberdade. A idade esquelética é considerada o registro fiel da idade biológica ${ }^{2,9,11,29}$, sendo desta forma o método mais usado na avaliação do crescimento craniofacial. Assim, as informações obtidas a partir dessa análise têm sido de grande valia para os profissionais de Ortodontia e Ortopedia Facial, auxiliando no planejamento e na melhor conduta terapêutica ${ }^{25}$.

A análise da radiografia carpal ainda hoje é muito utilizada, graças ao grande número de centros de ossificação em um local pequeno e de fácil técnica

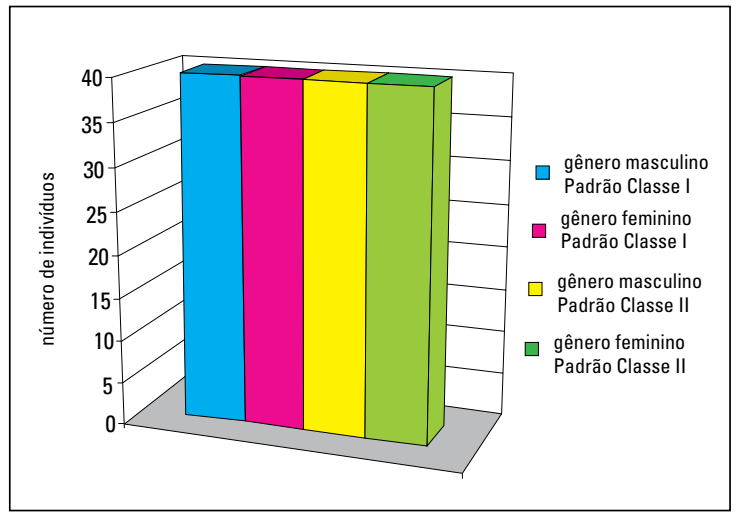

GRÁFICO 1 - Totalização da amostra estudada de indivíduos dos padrões Classes I e II dos gêneros masculino e feminino.

Tabela 1 - Resultados da Análise de Variância baseados num modelo com 3 fatores (Gênero, Classe e Fase) na avaliação da influência das medidas de Co-A.

\begin{tabular}{cccc}
\hline fonte de variação & g.l. & $\mathbf{F}$ & $\mathbf{p}$ \\
\hline fase & 5 & 4,02 & $\mathbf{0 , 0 0 1 6}$ \\
classe & 1 & 0,08 & 0,7758 \\
gênero & 1 & 1,60 & 0,2077 \\
fase x classe & 5 & 0,65 & 0,6611 \\
fase x gênero & 5 & 1,23 & 0,2981 \\
classe x gênero & 1 & 3,30 & 0,0706 \\
fase x classe x gênero & 5 & 1,24 & 0,2895 \\
\hline
\end{tabular}

Nota: F: Estatística do teste da Análise de Variância.

g.l.: Grau de liberdade/probabilidade de significância do teste da Análise de Variância. 
radiográfica ${ }^{7,29}$. Entretanto, acompanhando uma tendência atual, a preocupação de alguns autores com a quantidade de radiação ionizante aplicada ao paciente sugere métodos alternativos para a determinação da idade esquelética, como a avaliação das fases de maturação das vértebras cervicais visualizadas nas radiografias cefalométricas laterais ${ }^{2,9,11,28}$.

O método para estabelecer a relação esquelética entre maxila e mandíbula utilizado neste trabalho está de acordo com os trabalhos de Jacobson ${ }^{12,13,14}$; e Canuto $^{4}$, os quais constataram que apesar do ângulo ANB ser o método mais utilizado pela maioria dos profissionais no meio ortodôntico para o estabelecimento desta relação entre maxila e mandíbula, em indivíduos onde há alterações no posicionamento da base do crânio, especificamente na área do ponto $\mathrm{N}$ (násio) o valor encontrado poderá não ser o correto. Dessa maneira, serão necessários métodos adicionais, como a avaliação Wits, para a correta ve- rificação do relacionamento sagital entre maxila e mandibula. Portanto, em alguns pacientes, que por meio da medida ANB poderiam ser classificados com uma aparente relação de Classe II esquelética, ao serem submetidos à avaliação Wits poderá ser constatada uma informação errônea. Desse modo, a associação desses dois métodos de análise sagital entre maxila e mandíbula para se estabelecer a correta relação esquelética foi um fator determinante de inclusão na amostra deste trabalho.

Os resultados de Coughi ${ }^{5}$ com indivíduos padrões Classe I e II, do gênero feminino, na faixa etária de 12 a 27 anos em média, demonstraram haver uma semelhança no comprimento efetivo da face (Co-A) nos dois grupos estudados, no início, durante e dez anos após a conclusão do tratamento ortodôntico. Estes achados concordam com os resultados desta pesquisa, que também demonstrou existir pouca variação no comprimento efeti-

Tabela 2 - Análise descritiva e comparativa entre as variáveis gênero, classe esquelética e fase, quanto às médias das medidas de Co-A.

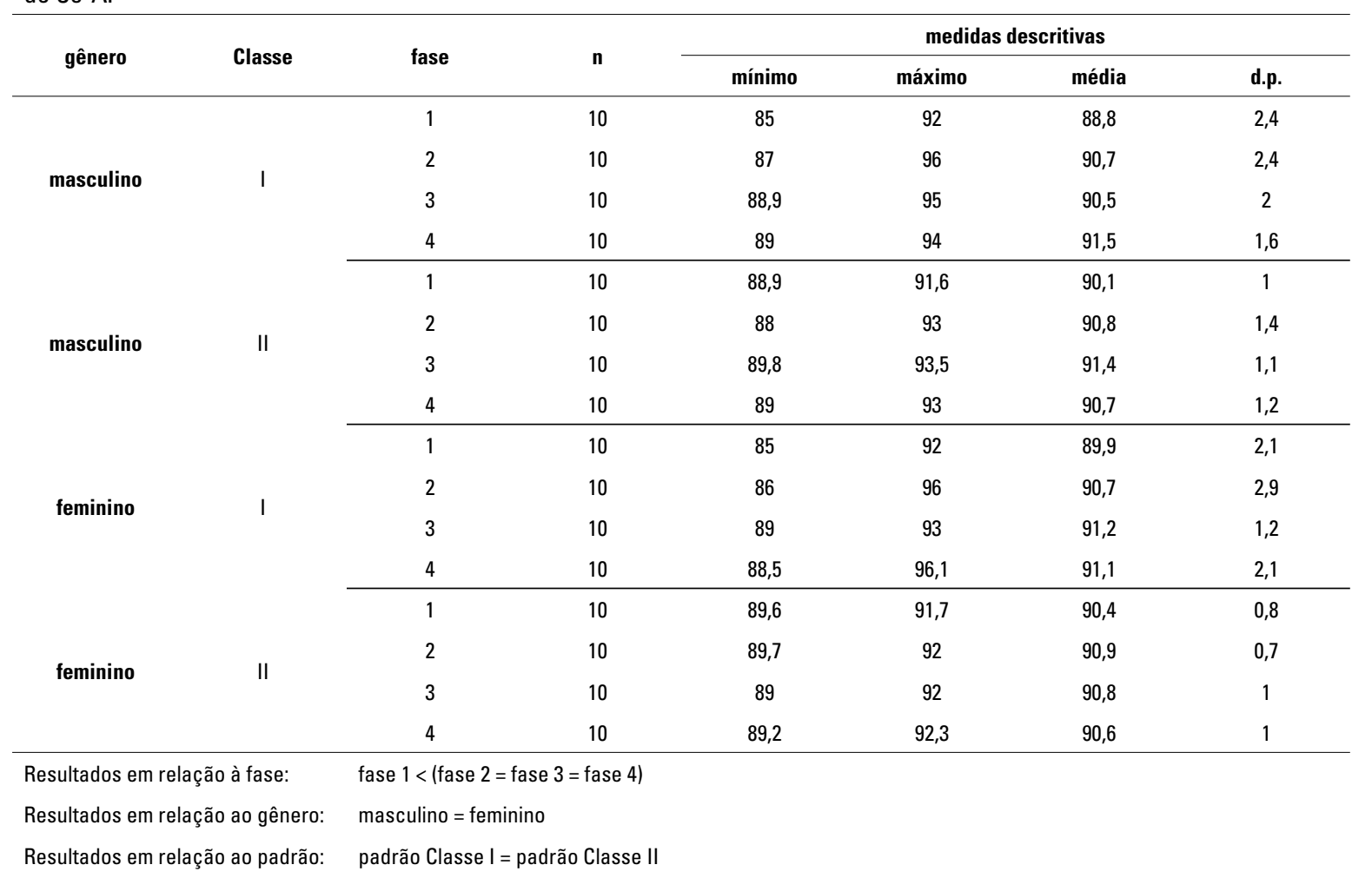




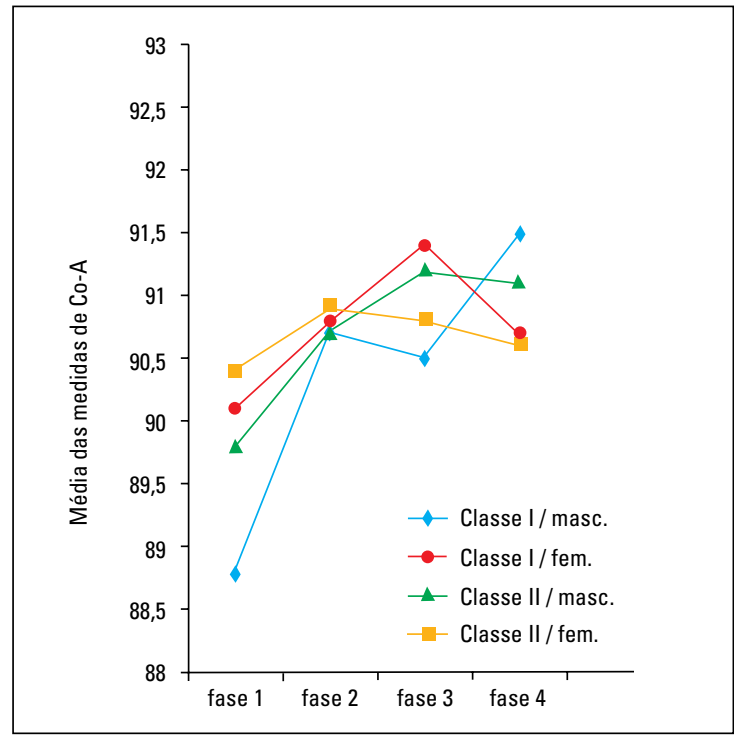

GRÁFICO 2 - Análise descritiva e comparativa entre as variáveis gênero, padrão esquelético e fase, quanto às médias das medidas de Co-A.

vo da face média (Co-A) em indivíduos do gênero feminino apresentando padrões Classes I e II.

Em um estudo cefalométrico com quarenta indivíduos padrão Classe I, dos gêneros masculino e feminino, leucodermas, na faixa etária de onze a quinze anos, Prates et al. ${ }^{23}$ obtiveram como resultado um comprimento da maxila (Co-A) maior estatisticamente no gênero feminino. Isto discorda dos resultados de nossa pesquisa, onde foi encontrado um comprimento da maxila (Co-A) estatisticamente comparável entre os gêneros feminino e masculino de indivíduos padrão Classe I.

Este trabalho também concorda com os resultados de Prata et al. ${ }^{22}$, que avaliaram o comprimento efetivo da face média por meio da medida Co-A em indivíduos dos gêneros masculino e feminino, na faixa etária dos sete aos treze anos, no início e pico do surto puberal, utilizando para a pesquisa uma amostra de 93 radiografias carpais e 186 radiografias cefalométricas laterais. Constataram que não houve diferenças estatísticas para a medida Co-A entre os gêneros

É relevante ressaltar o trabalho de Pinzan et al. ${ }^{21}$, que correlacionaram dois estudos sobre o crescimento maxilo-mandibular, utilizando as medidas
Co-A e Co-Gn. Os autores concluíram que a maxila (Co-A) revelou um comprimento menor por volta dos cinco anos para o gênero feminino, tendo esta medida se comportado de maneira semelhante dos cinco aos onze anos para ambos os gêneros. Dos onze aos treze anos de idade houve um crescimento bastante discreto e similar não significante, tanto para o gênero masculino como para o feminino. Este fato concorda com os resultados obtidos neste trabalho para uma amostra com faixa etária de sete aos treze anos de ambos os gêneros e que também não apresentaram diferenças estatisticamente significantes entre os gêneros. Segundo os autores, seria de suma importância realizar-se pesquisas com amostras de faixas etárias maiores, a fim de se avaliar melhor o comportamento dessas medidas.

Entretanto, Generoso ${ }^{8}$ relatou existirem diferenças entre indivíduos padrão Classe I e padrão Classe II, onde estes últimos apresentaram maturação das vértebras cervicais mais atrasadas em relação aos indivíduos padrão Classe I. Estaria essa alteração relacionada com a maxila?

Nosso trabalho revelou que a medida Co-A (comprimento efetivo da face média ou da maxila) não apresentou diferenças estatisticamente significantes entre indivíduos padrão Classes I e II, apresentando as mesmas fases de maturação das vértebras cervicais.

Dessa forma, estes resultados despertam alguns questionamentos: a maxila pelo fato de ser um osso fixo no crânio, sem mobilidade, estaria menos sujeita às alterações posturais da mandíbula e coluna cervical?

Certamente a resposta para este questionamento virá de futuras pesquisas com novas metodologias, etnias, faixas etárias maiores e utilizando-se também outras medidas cefalométricas.

Deve-se salientar também os trabalhos de Sadowsky ${ }^{25}$, Baccetti et al. ${ }^{3}$ e Franchi et al. ${ }^{6}$, que lembram a importância do restabelecimento equilibrado do sistema estomatognático, por meio de tratamentos com a utilização de dispositivos ortopédicos, permitindo assim adequada harmonia entre maxila e 
mandíbula. O tempo ideal para a aplicação deste protocolo de tratamento seria especificamente entre as fases 3 e 4 de maturação das vértebras cervicais, que correspondem aproximadamente ao pico da curva de crescimento puberal ${ }^{3,6,20}$.

\section{CONCLUSÕES}

Diante da metodologia e amostra utilizadas, bem como dos resultados obtidos, conclui-se que:

1) Não houve diferença estatisticamente significante na variação da medida Co-A entre indivíduos apresentando padrão Classe I e padrão Classe II, dos gêneros masculino e feminino na faixa etária estudada.

2) A média da medida Co-A na fase 1 (iniciação) de maturação óssea das vértebras cervicais mostrou-se estatisticamente menor em relação às demais fases 2 (aceleração), 3 (transição) e 4 (desaceleração) nos dois grupos estudados.

\title{
Cephalometric evaluation in lateral norm between skeletal Class I and II individuals with the bone maturation of the cervical vertebraes
}

\begin{abstract}
Aim: to discover the existence of differences in the maxilla length ( Co-A) among individuals of the male and female genres, leucoderms, presenting skeletal Class I and Class II, in the age group from seven to thirteen years, presenting the same phases of maturation of the cervical vertebraes respectively. Methods: the sample was formed by 160 radiographics lateral cefalometrics of individuals without previous orthodontic or orthopedic facial treatment. Results: the results showed no statistical significant differences between the individuals with skeletal Class I and Class II, nor among the male and female genres. Just the variation of the Co-A measure in the phase 1 (initiation) of maturation of the cervical vertebraes was statistical smaller than the other phases $(2,3$ and 4$)$ in the two studied groups. Conclusions: with that, we concluded that so much individuals presenting skeletal Class I as Class II, of the male and female genres, they present similar maxilla length, not having influence of the phases of bone maturation of the cervical vertebraes.
\end{abstract}

Key words: Maxillary length. Skeletal Class II. Bone age. Cervical vertebraes.

\section{REFERÊNCIAS}

1. ARAÚJO, T. S. S. Estudo comparativo entre dois métodos de estimativa da maturação óssea. 2001. $101 \mathrm{f}$. Dissertação (Mestrado em Odontologia, Área de Concentração em Radiologia Odontológica)-Faculdade de Odontologia de Piracicaba Universidade Estadual de Campinas, Campinas, SP, 2001.

2. ARMOND, M. C.; CASTILHO, J. C. M.; MORAES, L. C. Estimativa do surto de crescimento puberal pela avaliação das vértebras cervicais em radiografias cefalométricas laterais. Ortodontia São Paulo, v. 34, n. 1, p. 51-60, 2001.

3. BACCETTI, T. et al. Treatment timing for Twin-block therapy. Am J Orthod Dentofacial Orthop, St. Louis, v. 118, no. 2, p.159-170, Aug. 2000.

4. CANUTO, C. E. Estudo comparativo entre a análise "Wits" (University of the Witwatersrand) e "ângulo ANB", na avaliação cefalométrica das relações ântero-posteriores das bases apicais, em casos de oclusão normal. 1981. 58 f. Dissertação (Mestrado em Odontologia, Área de Concentração em Ortodontia)-Faculdade de Odontologia da Universidade de São Paulo, São Paulo, 1981.

5. CUOGHI, O. A. Avaliação cefalométrica do tratamento e dez anos após, utilizando as medidas da análise de McNamara Jr.: Co-A, Co-Gn, Dif.MM e AFAl, em pacientes do sexo feminino tratadas ortodonticamente com extração de quatro pré-molares: estudo longitudinal 1991. 104 f. Dissertação (Mestrado em Odontologia, Área de concentração em Ortodontia)-Faculdade de Odontologia da Universidade de São Paulo, Bauru, 1991

6. FRANCHI, L.; BACCETTI, T.; McNAMARA, J. A. Mandibular growth as related to cervical vertebral maturation and body height. Am J Orthod Dentofacial Orthop, St. Louis, v. 118, no. 3 p. 335-340, 2000.

7. GARCÍA-FERNANDEZ, P.; TORRE, H.; FLORES, L.; RHEA, J. The cervical vertebrae as maturation indicators. J Clin Orthod, Boulder, v. 32, no. 4, p. 221-225, 1998. 
8. GENEROSO, R. C. Avaliação radiográfica comparativa das fases de maturação das vértebras cervicais em pacientes com padrão classe I e classe II esqueléticos. 2002. 125 f. Tese (Doutorado em Biopatologia Bucal, Área de concentração em Radiologia)-Faculdade de Odontologia de São José dos Campos, Universidade Estadual Paulista, São José dos Campos, 2002 .

9. GENEROSO, R. et al. Estudo da correlação entre a idade cronológica e a maturação das vértebras cervicais em pacientes em fase de crescimento puberal. Revista Dental Press Ortodon Ortop Facial, Maringá, Maringá, v. 8, n. 4, p. 19-36, jul./ago. 2003.

10. HASSEL, B.; FARMAN, A. G. Skeletal maturation evaluation using cervical vertebrae. Am J Orthod Dentofacial Orthop St. Louis, v. 107, no. 1, p. 58-66, 1995.

11. HELLSING, E. Cervical vertebral dimensions in 8,11 and 15 year-old children. Acta Odontol Scand, Oslo, v. 49, p. 207-213, 1991.

12. JACOBSON, A. The "Wits" appraisal of jaw disharmony. Am J Orthod Dentofacial Orthop, St. Louis, v. 67, no. 2, p. $125-138,1975$

13. JACOBSON, A. Application of the "Wits" appraisal. Am J Orthod Dentofacial Orthop, St. Louis, v. 70, no. 2, p. 179-189, 1976.

14. JACOBSON, A. Update on the Wits Appraisal. Angle Orthod, Appleton, v. 58, p. 205-219, 1988.

15. JANSON, G. R. P. Estudo longitudinal e comparativo do crescimento facial dos 13 aos 18 anos de idade em jovens brasileiros leucodermas, utilizando a análise cefalométrica de McNamara Jr. 1990. 138 f. Tese (Doutorado em Ortodontia)-Universidade de São Paulo, Faculdade de Odontologia de Bauru, Bauru, 1990

16. LAMPARSKI, D G Skeletal age assessment utilizing cervical vertebrae.1972. $164 \mathrm{f}$. Dissertation (Master of Dental Science)Faculty of the School of Dental Medicine, University of Pittsburgh, Pittsburgh, 1972

17. McNAMARA JR., J. A. A method of cephalometric evaluation. Am J Orthod, St. Louis, p. 449-469, 1984

18. MITANI, H.; SATO, K. Comparison of mandibular growth with other variables during puberty. Angle Orthod, Appleton, v. 62 no. 3, p. 217-22, 1992

19. MORAES, L. C. et al. Idade óssea: considerações a respeito de sua estimativa. Rev Gaúcha Odontol, Porto Alegre, v. 42, n. 4 p. 201-203, 1994.

20. O'REILLY, M. T: YANNIELLO, G. J. Mandibular growth changes and maturation of cervical vertebrae: a longitudinal cephalome- tric study. Angle Orthod, Appleton, v. 58, no. 2, p. 179-184, 1988

21. PINZAN, A. et al. Estudo do crescimento maxilomandibular em jovens leucodermas com oclusão normal, de ambos os sexos, utilizando as medidas Co-A, Co-Gn, Dif. Mand/Max e AFAI. Ortodontia, São Paulo, v. 26, n. 2, p. 75-80, 1993.

22. PRATA, T. H. C. et al. Estudo do crescimento maxilar e mandibular na fase de aceleração do surto puberal. Revista Dental Press Ortodon Ortop Facial, Maringá, v. 6, n. 4, p. 19-31, 2001.

23. PRATES, N. S. et al. Crescimento cranio-facial e maturação óssea: estudo em indivíduos dotados de oclusão normal. RGO Porto Alegre, v. 30, n. 4, p. 261-268, 1982

24. RIEDEL, R. A. The relation of maxillary structures to cranium in malocclusion and in normal occlusion. Angle Orthod, Apple ton, v. 22, no. 3, p. 142-145, 1952.

25. SADOWSKY, P. L. Craniofacial growth and the timing of treatment. Am J Orthod Dentofacial Orthop, St. Louis, v. 113, no. 1, p. 19-23, 1998.

26. SANTOS, S. C. B. N.; ALMEIDA, R. R. Estudo comparativo de dois métodos de avaliação da idade esquelética utilizando telerradiografias em norma lateral e radiografias carpais. Ortodontia, São Paulo, v. 32, n. 2, p. 33-45, 1999.

27. SILVA FILHO, O. G.; FREITAS, S. F.; CAVASSAN, O. A. Prevalência de oclusão normal e má oclusão em escolares da cidade de Bauru-SP. Rev Odontol USP, São Paulo, v. 4, n. 3, p.189-196,1990.

28. SMITH, R. J. Misuse of hand-wrist radiographs. Am J Orthod St. Louis, v. 77, no. 1, p. 75-78, 1980.

29. TAVANO, O.; FREITAS, J. A. S.; LOPES, E. S. Comparação entre duas tabelas de avaliação de idade biológica através do desenvolvimento ósseo. Clin Pediatr, Philadelphia, v. 6, p. 7-21, 1982

30. TAVANO, O.; ARMOND, M. C.; GENEROSO, R. Maturação das vértebras cervicais vistas através das radiografias cefalométricas laterais. Revista da ABRO, [s. I.], v. 1, n. 2, p. 15-24, 2000.

31. URSI, W.: MCNAMARA JR., J. A. Crescimento craniofacial em pacientes apresentando maloclusões de Classe II e oclusão normal, entre os 10 e 12 anos de idade. Revista Dental Press Ortodon Ortop Facial, Maringá, v. 2, n. 5, p. 49-59, 1997.

32. WOODSIDE, D. Crescimento maxilar e mandibular após alteração do modo respiratório. Ortodontia, São Paulo, v. 27, n. 3, p. 95-114, 1994

33. ZHANG, Y.; WANG, B. Observation of cervical vertebrae and estimation of their bone age. Zhonghua Kou Qiang Yi Xue Za Zhi, Beijing, v. 32, no. 3, p.152-154, 1997.
Endereço para correspondência

Alexandre Medeiros Vieira

Rua Presidente Álvaro Costa, 109 - ap. 501- Centro

CEP: 37.002- 310 - Varginha/MG

E-mail: amvieira@uai.com.br 